\title{
Erratum to: Nordic Contributions in IS Research
}

\author{
Susanne Stigberg ${ }^{(凶)}$, Joakim Karlsen, Harald Holone, \\ and Cathrine Linnes \\ Østfold University College, Halden, Norway \\ susanne.k.stigberg@hiof.no
}

\section{Erratum to: \\ S. Stigberg et al. (Eds.): \\ Nordic Contributions in IS Research, LNBIP 294, DOI: 10.1007/978-3-319-64695-4}

The name of the following editor Joakim Karlsen has been misspelled. The correct information is given below.

Joakim Karlsen

The updated online version of the book can be found at http://dx.doi.org/10.1007/978-3-319-64695-4 